\title{
Planificación de áreas ambientales protegidas para el turismo
}

\section{Omar Ovalles}

\section{Introducción}

En este trabajo se presenta la experiencia de diez años en la planificación y manejo de áreas ambientales protegidas desde una óptica latinoamericana.

Las líneas que siguen reflejan varias experiencias en el campo del turismo, en donde se ha trabajado con comunidades en su identificación, concepción y manejo y no pretende ser más que una guía para estimular la reflexión en otros países y contextos. El trabajo está abierto a las observaciones de todos los interesados.

\section{I.- Mas allá de la conservación como resguardo genético}

En las estrategias de conservación de la biodiversidad en nuestros países, tienen hoy activa presencia algunos entes internacionales, gubernamentales $y$ fundaciones privadas, preocupadas por la conservación del ambiente y que pretenden poner bajo su tutela y cuidado importantes recursos genéticos de las áreas protegidas.

Esta estrategia se viene dando a lo largo $y$ ancho de nuestro continente mediante el funcionamiento de programas de conservación ambiental con fondos provenientes de corporaciones privadas del mundo desarrollado, convenios de canje de deuda externa (SWAPS) y otras modalidades. Analicemos el significado ecológico y económico de estas vías, para luego plantear su vinculación con la actividad turística posible y deseable en las áreas ambientales protegidas.

Ante el evidente deterioro ambiental de nuestros países, se han sugerido varias modalidades de protección y cuidado. Este planteamiento viene haciéndose estratégicamente en nuestros países mediante cursos y asesorías, que tratan de implantar la idea de que el manejo internacional es mejor que el nacional. 
Este enorme potencial genético requiere de ser protegido y controlado por las firmas comerciales que hoy pueden valorarlo, utilizarlo y emplean para ello algunas fundaciones internacionales de conservación ambiental muy vinculadas a las grandes firmas de la bioingeniería. Vale la pena destacar que estas fundaciones están vinculadas directamente a enormes empresas transnacionales agroquímicas, farmacéuticas y agroalimentarias como aparece en el ejemplo del cuadro que sigue (№ 1)

\section{Cuadro № 1}

Vinculación entre grandes firmas de bioingeniería y el World Resourse Institute (WRI)

\begin{tabular}{|l|l|}
\hline $\begin{array}{c}\text { DONANTES DEL } \\
\text { WRI }\end{array}$ & $\begin{array}{c}\text { MAS GRANDES } \\
\text { FIRMAS BIOINGE- } \\
\text { NIERIA DEL } \\
\text { MUNDO }\end{array}$ \\
$\begin{array}{l}\text { SHELL } \\
\text { MONSATO } \\
\text { DUPONT }\end{array}$ & MONSATO \\
\hline HOESCHT & DUPONT \\
\hline PFIZER & HOESCHT \\
\hline TEMECO & PFIZER \\
\hline CELANECE & TEMECO \\
\hline OCCIDENTAL & CELANECE \\
\hline PETROLEUM & OCCIDENTAL \\
\hline ATLANTIC & PETROLEUM \\
\hline RICHFIELD & ATLANTIC \\
\hline
\end{tabular}

Fuente: Prospecto del Word Resource Intitute, 1998 y Seed for change, Fundation Dag Hammarkhold, Suecia, 1998.
Esta estrategia de "acaparamiento genético" está concebida para apoyar los requerimientos de las grandes firmas de Ingeniería Genética y Biotecnológica que requieren del Tercer Mundo los Bancos Germoplastas para reforzar los híbridos de alta tecnología utilizados en agricultura y para la síntesis de medicamentos y otros compuestos industrializados.

Actualmente se desarrolla un gran esfuerzo a nivel mundial para controlar los recursos genéticos (Cuadro № 2). A medida que se reconoce la importancia de los recursos genéticos en el mundo, la diversidad va disminuyendo y sólo subsisten las especies que poseen interés. Las compañías multinacionales han sugerido que la vida debe estar sujeta a patente para garantizar los fondos para su conservación.

Una manera que utilizan estas compañías para ejercer control es por medio de las patentes de especies o genes. En Estados Unidos ocurrió que algunas compañías querían tener derecho de propiedad sobre cierta variedad de plantas. Una vez que se permitió esto se patentó una "variedad"; más tarde las compañías manifiestan que también se les debe permitir patentar organismos animales, ya que legalmente no hay mayor diferencia.

En Estados Unidos, Canadá y muchos países de Europa, los microorganismos y las plantas pueden ser patentados. Luego, el siguiente paso fue patentar animales. En abril de 1987, el gobierno de los EEUU autorizó las patentes sobre animales. Primero, se aplicaron patentes sobre mariscos y más tarde sobre vacas y después, ¿por qué no patentar genes individuales?

Por estas razones, se plantea una política de resguardo de la biodiversidad asociada a las comunidades locales y pensada como parte integrante del turismo ecológico que requieren de ellas para su desarrollo sustentable; no como "islas biológicas". La Convención sobre Biodiversidad signada en la ECO 92 apuntala 
algunas de estas iniciativas y por eso hubo muchos problemas a la hora de su firma.

En este sentido, los países tropicales deberían plantearse las siguientes interrogantes:

¿Cómo estimular líneas de investigación que no apunten hacia la protección ambiental al servicio de la artificialización de la vida?

\section{Cuadro № 2}

Ubicación del 80\% la diversidad biológica en el mundo

\begin{tabular}{|l|l|}
\hline RANGO & \multicolumn{1}{|c|}{ PAIS } \\
\hline 1 & BRASIL * \\
2 & COLOMBIA ** \\
3 & INDONESIA \\
4 & CHINA \\
5 & ECUADOR *** \\
6 & INDIA \\
7 & MALASIA \\
8 & MEXICO \\
9 & PERU**** \\
10 & VENEZUELA \\
11 & ZAIRE \\
12 & MADAGASCAR \\
13 & AUSTRALIA \\
\hline
\end{tabular}

NOTAS: Una de cada cinco especies primates, 5,500 plantas con fiores, $22 \%$ más anfibios que el resto, tres veces más de peces de aguas dulces, segundo en la lista de reptiles, tercero en la lista de mamíferos.

** Primer lugar en aves, segundo en plantas y quinto en el resto de las categorías.

*** Primer lugar en mamíferos, más del $50 \%$ de especies que Asia.

**** $93 \%$ de primates, 233 reptiles, $98 \%$ de palmeras, 131 ranas.
En 1985, cuando se realiza el Primer Encuentro Nacional de Serengueiros de Brasil, esta modalidad adquiere relevancia internacional. Una reserva extractivista no es un asentamiento, sino una regulación de una propiedad históricamente adquirida por una población que ha utilizado productos de las selva no madereros para su subsistencia y comercialización en forma compatible.

Ello no significa sólo el respeto a las formas tecnológicas tradicionales, sino incluye el ecosistema sustentablemente. Del mismo modo, la investigación científica no se concibe sólo como un instrumento para preservar el stock genético, sino como una manera de revalorizar los recursos naturales para beneficio de los legítimos moradores.. En este caso hay una clara concordancia con los objetivos de la protección ambiental, mas no con algunos de los grandes proyectos de control genético.

Un variado número de productots pueden ser extraídos en forma sostenida de una reserva extractivista en la selva tropical: caucho, balatá, chiquichique, castañas, aceites, hierbas medicinales, palmito, almendras, fibras vegetales. Estos pueden ser complementados con caza selectiva y controlada, pesca y artesanía y transformación semi-industrial, ecoturismo y pequeña cría de animales autóctonos (zoocriaderos).

Esta actividad ha tenido un tratamiento marginal en la definición de políticas de desarrollo. En Venezuela tímidos proyectos de rescate de fibras autóctonas, cultivo de pimienta, revalorización de conuco o del caucho, se alejan de esta tendencia.

Sucede que los grandes proyectos de inversión industrial y la minería generan más ingresos y tienen, por ende, mayor aceptación como opciones viables. Si estos no son factibles o viables, prima entonces el fácil criterio de decretar un parque nacional y con él, la conservación en abstracto o con un sentido de utilidad biotecnológica. 
Por el contrario, fueron los practicantes de este tipo de actividades extractivistas y en especial, los pobladores originarios, los que se han opuesto a la presencia avasalladora de los modelos de protección ambiental anteriormente comentados.

La actividad extractivista intrínsecamente es respetuosa de la dinámica ecológica; por ejemplo, en el caso del caucho, requiere de la conservación del árbol (Hebea Brasilence) cuya explotación se hace en forma controlada y aleatoria. Similar circunstancia se da en el caso de las fibras, las palmeras, hierbas y pequeños animales.

La productividad de cada especie y su tasa de reproducción son los indicadores que determinan la ganancia, y no al contrario. Esto es, en sí, una ventaja ecológica de este particular proceso productivo y de ocupación del territorio.

Esto genera, además, un extraordinario patrón de dispersión dentro de la selva, lo que favorece su protección activa. Recuérdese que la mayoría de los ecosistemas tropicales poseen una baja capacidad de carga.

Otras extracciones como las de castaña - fibras vegetales, ameritan hacer grandes recorridos en la selva, lo que facilita la recuperación de las especies explotadas. El ciclo económico se adapta al ecológico, y no ocurre lo contrario.

Esto también implica un concepto diferente de propiedad territorial o de tenencia de la tierra, ya que esta modalidad de extracción no reconoce linderos o tamaños mínimos; se centra más en la posibilidad de utilizar sostenidamente una especie que en detentar la propiedad absoluta de una porción de suelo.

En Brasil, estas novedosas formas de propiedad se generan aceleradamente e incluyen áreas de pesca y caza controlada, recolección de frutas, látex, hierbas, etc. Su centro es la vivienda del productor y sus linderos varían año a año según la recuperación de la selva.
Curiosamente, una extraña simbología surge para orientarse en esta masa forestal que es un espacio de ocupación, pero no de asentamiento rígido. Se plantea así un manejo ecológico que requiere de nuevas formas de propiedad y ocupación del territorio.

Sin embargo, es evidente que hoy en día, subsisten graves problemas derivados de las relaciones de trabajo, remuneración, e incluso, de actividades políticas fuertemente injustas. He aquí la importancia del Estado para derogar códigos de contratación o para promover otras relaciones sociales más justas; para dar lugar así, al surgimiento de unidades de producción y comercialización más democráticas en su gestión.

La actividad extractivista surge inspirándose en la forma indígena de "apropiación" de los ecosistemas, que no es natural como piensan muchos ecólogos, sino que está adaptada a una estrategia de sobrevivencia muy especial y aparece como reacción al modelo de colonización y de ocupación del territorio en parcelas de tierras definidas de antemano.

La actual división de la tierra por tamaño y la figura jurídico institucional que esto implica no es compatible con la dinámica de los ecosistemas. Por lo tanto, reservas extractivistas chocan con un concepto de propiedad territorial y de manejo de recursos naturales que a todas luces, poseen su dinámica y propia razón.

En este caso no se trata de dimensionar la tierra para poseerla, sino, ordenarla para garantizar la continuidad de la actividad extractivista, evitando la invasión de mineros, urbanizadores y madereros.

Del mismo modo, su tamaño no se debe calcular en térmicos físicos, sino, biopoblacionales y por lo tanto, es y debe ser flexible.

Este enfoque implica una modificación de la normatividad legal vigente, ya que esta categoría de reserva extractiva no coincide con la reserva forestal, parque nacional, áreas 
protectoras $u$ otras. Todas ellas protegen al ambiente del hombre, pero no hay ninguna que modifique la conducta del hombre para mantenerse en forma sustentable en el ambiente.

En este caso, se trata de preservar el uso de enormes áreas naturales de las cuales depende, o debe depender, la subsistencia de una importante población local marginada del desarrollo del país, ya sea voluntaria o deliberadamente.

\section{En este sentido, los países tropicales debieran plantearse los siguientes problemas:}

¿Cómo evaluar las figuras jurídicas para proteger la naturaleza en función de las estrategias para aprovechar los recursos naturales de forma sustentable?

¿Cómo promover y seleccionar las tecnologías apropiadas para llevar adelante modalidades productivas asociadas a una dimensión ambiental?

¿Cómo evaluar el impacto ambiental y socioeconómico de estas nuevas prácticas de asentamiento humano?

¿Cómo evitar la colisión de los modelos de asentamiento humano que ellas implican?

¿Cómo articular las diferentes figuras jurídicas, sean de protección o de uso, bajo una modalidad integradora?

Para responder estas preguntas hace falta reafirmar el sentido de la protección de ambiente y su vinculación con el turismo sustentable, a fin de validar opciones que finalmente permitan establecer las bases teóricas y metodológicas de una red de áreas naturales protegidas y de producción autofinanciables por sí mismas, vía ecoturismo, y alejadas de posibles convenios de este tipo, con claras repercusiones dañinas.

Por último, debemos recolectar argumentos para exigir de los gobiernos políticas económicas que no atenten contra la integridad y seguridad ecológica del país y favorezcan el manejo de su ambiente, comandado por las instituciones públicas nacionales, regionales y locales. En América Latina, como refiere Leff, el ambiente es un potencial de desarrollo y no algo para conservar egoístamente para unos pocos. Leff (1989).

Para lograr esto hace falta redefinir algunos conceptos teóricos sobre protección ambiental y vincularlos a los conceptos de turismo sustentable. Esto haremos en la siguiente sección con el fin de plantear una serie de estrategias y metodologías válidas para definir AREA AMBIENTALES, una vía regional de desarrollo del turismo sustentable con protección ambiental implícita.

\section{II.- Metodología}

\subsection{Marco teórico}

2.1.1. Aspectos generales - Para fundamentar la creación de un sistema de áreas ambientales protegidas para el ecoturismo, hace falta también conformar un soporte conceptual estructurado.

Hace falta por lo tanto establecer las interrelaciones presentes entre las diversas categorías, indicando los variados niveles de escala en la cual se presentan. Es necesario recordar que esta conceptualización, una vez operacionalizada, servirá para determinar los indicadores ambientales que serán sujetos de atención por un monitoreo ambiental que garantice su integridad bajo uso turístico.

Dentro del concepto de ambiente, entendido según Pesci (1990), como "un marco de posibles relaciones y no una colección de 
objetos", circunscribimos el término de realidad ambiental "como aquellos condicionantes sensibles y perceptibles que son fundamentales para la realización de un grupo humano determinado". Ovalies (1993). Por eso la protección ambiental está consustanciada con nuestro destino como seres ambientales, no es ajena a nosotros $y$ muchos menos inhumana.

Ante esta realidad ambiental, se han asumido una serie de posturas que van desde las más voluntaristas, como la planificación ambiental y ordenamiento del territorio, hasta las más liberales como las actuales visiones economicistas de los recursos naturales.

Si partimos de la base de que la dinámica social determinaría la ocupación, el uso y degradación de los recursos, sólo nos limitamos a proponer un espacio para experimentar y hacer realidad nuevas experiencias sociales concretas de desarrollo sustentable.

La figura de las áreas ambientales, y su soporte técnico-organizacional, se vincula directamente al concepto de seguridad ambiental definido por Wilchez Chaus (1989): "Estado psicosocial de garantía plena de disfrute de los principales Derechos Ambientales".

En este caso, reconocemos las variadas facetas de este concepto: económica, social, cultural, ecológica, etc. y no suscribimos la tesis de Baquedano (1989) que la emplea para ayudar a superar los conceptos de seguridad vinculados sólo a la temática militar o policial.

Sin tratar de negar estos irrenunciables contenidos, la Seguridad, en los momentos actuales de clara distensión entre las grandes potencias, exige ser complementada con nuevos contenidos que la relacionan en un mundo necesariamente más impredecible, pero con muy poca definición de aliados y adversarios.

No asumimos aqui la fácil tentación de negar la esencia de la institución militar y las doctrinas de seguridad y defensa nacional; lo cual sería una clara inconsecuencia en momentos en que en aras de una supuesta globalización (que en el fondo sólo representa los intereses de una gran potencia hegemónica), se debilitan los Estados Nacionales con sus políticas legítimas de custodia, defensa de su soberanía y en especial, de su patrimonio.

Creemos como Nils Castro (1989) que una doctrina de seguridad y defensa inspirada en un estilo nacional de desarrollo y discutida democráticamente en todas las instancias nacionales, de manera de que sea comprendida y aceptada, es la garantía, no sólo de la integridad (en sentido amplio) del patrimonio nacional, sino también, de futuros y deseables procesos de integración a nivel regional que tanto le hacen falta a nuestros países y que sólo son viables en una situación de clara autodeterminación política y económica.

Si a este concepto de Seguridad, como parte de un estilo de desarrollo nacional, le añadimos el componente axiológico de los Derechos Humanos, podemos tener la certeza de que difícilmente podría ser desviada hacia las clásicas situaciones autoritarias ocurridas en nuestro continente, ya sea en el extremo del nacionalismo más acérrimo, como del entreguismo más pueril.

Asumir la Seguridad Ambiental como un proceso de aprendizaje permanente de las variables vinculadas a los derechos humanos de primera, segunda y tercera generación nos lleva directamente a una concepción ecológica basada en el equilibrio dinámico, en la cual no existen situaciones estables, sino procesos muy dinámicos de cambios rápidos, impredecibles y con variadas consecuencias. Morin (1980).

Dentro de estos procesos es posible detectar períodos de resistacia en los cuales, las modificaciones más importantes son de tipo físico o físico-químico y las modificaciones biostáticas que son de tipo biológico o bioquímico.

Períodos alternantes en el tiempo son siempre acompañados de cambios de tipo social, ya sea en las manifestaciones económicas, políticas, ideológicas o culturales, en el sentido 
más amplio del término.

En este interesante "fluir de cambios", en el cual el grupo humano en cuestión es un componente más, se inscribe el concepto de seguridad ambiental.

Reconocer lo ambiental bajo esta percepción pasa por aceptar la prevalencia de los procesos probabilísticos por sobre los determinantes fijos y revalorizar la importancia de mantenerse informado de los cambios en tiempo real.

Esto implica, en términos prácticos, predisponer de un instrumento ágil y veraz de captación de información y de contrastación de ella con estándares y normas que hemos aceptado como la concretización de nuestros deseos.

Esta es la principal función del monitoreo ambiental; pero este proceso no debe ser visto como un simple acto técnico, sino que es profundamente educativo y por ende, político.

Educativo, porque se vincula al proceso de aprendizaje a partir de la vivencia de estos eventos que ya han ocurrido o pueden ocurrir. Político, porque implica el incremento en las capacidades humanas o grupales para tomar decisiones en función de los objetivos y misiones que soberanamente se han dado.

\section{Por estas razones, partimos de la base que:}

1. Los ecosistemas no tienden hacia un equilibrio predeterminado, sino que poseen variadas trayectorias con situaciones de equilibrio dinámico. El territorio debe ser un reflejo de ello.

2. La sociedad humana tiende a buscar este equilibrio dinámico, trata de recuperar su conocimiento para comprenderlo y armonizarse con este proceso para saber elegir, así, cuál de esas trayectorias más le conviene a corto, mediano y largo plazo. Este conocimiento es parte del acervo cultural del grupo humano, y es tan "recurso natural" como los otros que son observables y medibles en los ecosistemas.

3. En las actuales situaciones las acciones ambientales serán viables en la medida en que tomen en cuenta las posibilidades que el mercado deje y, por otro lado, los estímulos que desde el Estado, la sociedad política y la sociedad civil, se permiten.

No se trata de voluntarismo ciego, ni del Laisser Faire, sino de reconocer el peso de las determinantes externas en su justo valor a la hora de tomar decisiones y hacerlas realidad en base a acciones.

4. Los grupos humanos guían la búsqueda de sus intereses básicos en función de las representaciones que sobre el ambiente tienen sus integrantes. Estas representaciones, como productos culturales, se inscriben en contenidos de tipo simbólico, mítico, instrumental o fáctico y pueden ser, a veces, muy diferentes a los que realmente existen.

Por esta razón, la semiótica, la sicología, epistemología y en general, las ciencias de la comunicación, adquieren relevancia a la hora de asumir este enfoque.

5. Asumir este enfoque exige una actitud ética que se basa en la reflexión profunda para afianzar nuestros principios ambientales $y$ sociales y visualizarlos como guías de nuestra acción.

Por otro lado, exige el rescate de la observación, la medición y la constatación como instrumentos para catalizar activos procesos sociales locales, ante la irrupción de un proyecto de industrialización y de economía de servicios de alto desarrollo tecnológico.

En conclusión, para concordar con este enfoque se requiere asumir una posición valorativa de lo social, no como prevalencia del hombre sobre el resto de los componentes del ambiente, sino como ser biosicosocial 
consustanciado con su historia y su entorno.

Por otro lado, para poder identificar y operacionalizar las variables que se derivan de los conceptos teóricos mencionados, hace falta replantearse el marco jurídico, no como instrumento proteccionista, sino como recurso para ayudar a reconvertir y cambiar la lógica del turismo para que incorpore en su seno la dimensión ambiental del desarrollo sustentable.

\subsection{Aspectos metodológicos}

\subsubsection{Aspectos generales}

Dado que el objetivo de este trabajo es analizar la figura de áreas ambientales dentro de los procesos regionales del turismo, ocupación del territorio y la elaboración de una propuesta concreta que permita aplicar una serie de normas técnicas y criterios que minimicen los impactos ambientales del turismo, se procedió a emplear una metodología que, partiendo de categorías teóricas, pudiera llegar a recomendaciones operativas prácticas.

La metodología empleada contempló cinco fases, a saber:

1. Operacionalización del marco teórico partiendo de la definición de "seguridad ambiental", se reinterpretan una serie de variables de uso común en las ciencias ambientales, de manera que puedan dar cuenta de este estado. Se trata de una lectura informática de los componentes ambientales.

Estas variables son operativizadas posteriormente, en indicadores que pueden ser medidos cuando se lleve a cabo una caracterización de línea base de los recursos naturales y la ocupación del territorio del área en estudio.

2. Caracterización de Línea Base. Sistematizando la información proveniente de fuentes secundarias y realizando un chequeo de campo para validar alguna parte de ella, se procede a elaborar una serie de mapas de zonificación según sean los aportes o necesidades de información ambiental que tanto los componentes naturales o humanos poseen.

3. Estos mapas luego son analizados mediante el método de MAC HARG (1976) y las recomendaciones de la UNESCO (1994) y UICN (1993) para la definición de áreas ambientales protegidas para el turismo.

4. Análisis de Viabilidad: Estos resultados son vistos a la luz de los posibles impactos que los proyectos turísticos podrían causar a las áreas ambientales, para diseñar una estrategia de implantación con un alto grado de viabilidad.

5. Finalmente, se plantea un ente administrador de las variables e indicadores ambientales que nos permite saber si se están cumpliendo o no los preceptos del desarrollo sustentable y los ecosistemas no están perdiendo su resilencia.

El instrumento utilizado en este caso es el Grupo Ad Hoc Ambiental, el cual permite estructurar tras de si toda una serie de herramientas operativas que permiten sistematizar toda la información recopilada y procesada en las fases anteriores.

El Sistema de monitoreo, estructurado a partir del grupo ad hoc, se somete entonces al juicio y a la opinión de los actores sociales involucrados en esta misión a nivel local regional, de manera de obtener críticas y comentarios que permitan su perfeccionamiento.

Un paso importante de este trabajo fue la definición de las gradaciones de uso de áreas ambientales, lo cual se hizo revisando las metodologías de evaluación de capacidad de carga y las técnicas de análisis de visitantes. Asimismo, la visión informática de los ecosistemas cumple un papel relevante en la caracterización de línea base. Por tener una importancia fundamental en el trabajo se detallarán ampliamente en las próximas secciones. 
2.2.2. La delimitación de las áreas a partir del análisis de los flujos de información ambiental.

Para realizar la delimitación de áreas ambientales para el turismo se parte de los estudios de línea base y se identifican los flujos de información ambiental relevante entre los posibles componentes.

En América Latina podemos identificar áreas bajo régimen de protección especial, áreas posibles de conservar, áreas de amortiguación, áreas de corredores, áreas de restauración y las áreas turísticas.

Esto se hace tratando de demostrar que un sistema de áreas protegidas y de turismo, no acepta la definición de islas en un territorio ajeno a ellas, y lo que exige es la existencia de corredores que las unan o áreas de amortiguación o buffers que las protejan hacia las comunidades. Esto sí sería un Sistema Regional de áreas ambientales en el cual unas se complementan con las otras.

Las áreas adyacentes o de vinculación adquieren así el gran papel de viabilizar estos intercambios informáticos, ya sea de recursos vitales, bioindicadores, materiales genéticos, conocimientos, etc. Estas áreas serán Ilamadas "de ecoturismo" y exigen la concepción de una política especial que se concrete en programas y proyectos turísticos de nuevos tipos.

Bajo el enfoque de sistemas, estas áreas de ecoturismo serían de tipo "abierto", es decir, con intercambios frecuentes y significativos con su entorno.

Este entorno posee dos fuentes básicas de información: las áreas de protección ambiental y las áreas de ecoturismo. Sería deseable que las áreas de "ecoturismo" se ubiquen en áreas de fronteras, en ecotones que sirvan de límite entre áreas de protección y áreas no protegidas.
Las unidades de ecoturismo de estas áreas de proyección, serían además intensivas en el manejo de la información; es decir, bajo un esquema de experimentación a nivel comercial con un alto componente tecnológico apropiado y un importante insumo informático. Tales serian los casos de los proyectos pilotos, escuelas, granjas, viveros, zoocriaderos, estaciones experimentales, parcelas demostrativas, senderos, lodges, etc.

Este insumo informático tendría un flujo bidireccional hacia adentro, a fin de permitir que se instale un proceso productivo eficiente desde todo punto de vista.

Este enfoque busca superar la visión ambiental dominante que podemos llamar "proteccionista", la cual nos permite tener hoy en día, extensas áreas con aceptables condiciones de integridad ecológica, pero que en cierta forma, han ayudado a posponer por mucho tiempo, las necesarias reformas o reestructuraciones internas que requieren las unidades productivas del resto del territorio, para hacerlas intrínsecamente ambientales.

Hoy en día, cuando los efectos de la crisis económica o las propuestas de reconversión industrial, comercial y económica en general están siendo asumidas en casi todo el mundo, es el momento apropiado para propiciarlas con una intencionalidad ambientalista.

En este sentido, las técnicas de calidad total, tan en boga en las organizaciones de cualquier tipo, podrían incluir aspectos de calidad del ambiente o calidad de vida de los entornos de las unidades de ecoturismo.

Las técnicas de reducción de costos podrían estimular el reciclaje de productos 0 subproductos en una unidad de ecoturismo para minimizar la generación de desechos. La reingeniería podría ser asumida no sólo como búsqueda de la eficiencia productiva, sino también, para incursionar con éxito en el campo de las tecnologías apropiadas. 
Finalmente, técnicas como el "downsizing" podrían servir realmente para reducir las escalas de trabajo, distribuir las unidades para reducir las unidades más homogéneamente en el territorio para minimizar sus impactos ambientales y, en consecuencia, hacer posible los postulados de Schumaker en Lo pequeño es hermoso. (1976).

Es obvio que todas estas técnicas de reorganización del proceso turístico, al igual que otras tantas que surgirán en los próximos años, tienen una clara intencionalidad económica; abren hoy la posibilidad de cambiar las estructuras organizacionales y sus procesos para que podamos incluir, sin ningún temor, muchas reformas que haciendo un esfuerzo preventivo, minimizan los impactos ambientales, reduciendo sus causas y no sólo atacando las consecuencias.

Este proceso de reingeniería, que para nosotros podría servir para la reconversión ambiental, también es motivado por los profundos cambios que se vienen gestando en el mercado de consumidores de bienes y servicios "verdes"; sobre todo, por efectos de la publicidad $y$ mercadeo (es decir, por cambios en el volumen y tipo de información sobre bienes y servicios que posee el público) y por otro lado, por las consecuencias de haber masificado la educación ambiental y la acción política misma de los ambientalistas.

En el primer caso, es notorio cómo al menos en las enormes capas medias de la población, el mensaje publicitario comienza a perder efectividad y con eso, aparecen nuevas exigencias a los productos; más allá de la simple marca comercial o el eslogan publicitario.

Por esta razón, hemos visto cómo se comienza a exigir, además de precio, calidad, la información básica de los componentes del servicio e incluso, el tipo de proceso productivo que lo hizo realidad para ver sus riesgos y repercusiones ambientales.

Esto permite, por lo menos a nivel de ciertos sectores de consumidores ilustrados y con relativo poder de compra, ejercer cierta "soberanía del consumidor" y hacer sentir parte de sus exigencias a los propietarios de las unidades de producción.

Algunas exigencias ambientales en cuanto al tipo de empaque, componentes o repercusiones ambientales de los procesos productivos 0 de sus desechos parecen ser asumidos por algunos sectores de consumidores a la hora de comprar, con lo cual envían un claro mensaje indirecto a los productores de bienes y servicios para que cambien sus procesos tecnológicos.

En términos de mercadeo, aparece una situación con similares consecuencias cuando al reconocerse la segmentación de los mercados turísticos, se favorece una oferta de bienes $y$ servicios más diversificada $y$, por ende, más adecuada a la demanda y a sus entornos específicos.

En fin, ya sea por el lado de la oferta (reconversión económica) o la demanda (mercadeo y publicidad de nicho) están dadas las condiciones económicas para impulsar un proceso de reconversión que tantas veces ha sido propuesto: cambiar el sistema de producción económico para hacerlo ambientalmente sustentable, para que pueda interpretar e internalizar flujos de información.

Llegado a este punto, es necesario desmitificar otro paradigma profundamente arraigado en el vulgo ecológico y que no ha permitido avanzar en una efectiva política de compenetración de la sociedad con su ambiente; el paradigma del equilibrio ecológico.

Este concepto vago que inspira la política de preservación de ciertas áreas, presupone que ciertos espacios del territorio supuestamente aislados y alejados de la influencia humana significativa, podrían permanecer inalterables.

Este supuesto contradice las más actuales concepciones biológicas y por ende, las más avanzadas interpretaciones de los 
ecosistemas como supraorganismos vivos. Ver J.P. Lovelock GAllA, La Hipótesis tierra, (1990).

No hay nada más lejos de la realidad biológica, que el equilibrio de fuerzas y materias, el cual sólo se logra cuando cesa el flujo de la vida, es decir, cuando el organismo muere.

El proceso biológico implica confrontación, síntesis de fuerzas contrarias que pugnan, unas por mantener el metabolismo y las otras por reintegrar toda esta materia y energía al ámbito de donde surgió: el mundo físico-químico inanimado.

El equilibrio homeostático, es decir, aquel en donde paradójicamente el "desequilibrio constante" es la garantía de la integridad del organismo vivo, parece ser una mejor interpretación de estos procesos.

Sin embargo, es necesario destacar que el concepto de equilibrio ecológico ha servido en muchas ocasiones, para garantizar la integridad de muchas áreas naturales e incluso, iniciar procesos de preservación.

A pesar de ser un concepto limitado, que induce una falsa concepción de los procesos de la vida, hay que reconocer que permite estimular la búsqueda de ciertos objetivos ecológicos en ciertas comunidades, estados y empresas.

Por la razón anteriormente planteada, no es adecuado rechazarlo en términos operativos, sino más bien, para un diagnóstico acertado de alguna situación de algún ecosistema.

Siendo consecuentes con el planteamiento informático de la cuestión ambiental que desde el inicio de este informe intentamos presentar, vamos a tomar en cuenta el concepto de EQUILIBRIO DINAMICO como leit motiv del proceso de reconversión económica de las unidades productivas descritas y que proponemos asumir para el caso de las actividades existentes en las áreas ambientales protegidas, lugares adyacentes y en sus espacios regionales relacionados con ellas.

Este equilibrio dinámico como refiere E. Morín E. en su Ecología de la Civilización Técnica (1989), se favorece con la dinámica de la estructura informacional implícita que permite activar o desactivar los procesos esenciales de un ecosistema en su larga y azarosa marcha evolutiva.

Para cada una de estas tendencias y en especial para las combinaciones de ellas, existe un importante flujo de información que condiciona el comportamiento de los seres vivos, que permite la relación entre estos con su entorno y en especial, con sus factores fisiconaturales vitales y en mayor grado, garantiza este equilibrio dinámico que le da identidad a ese ecosistema a lo largo del año y de año en año, en la lenta pero sostenida marcha evolutiva.

Para poder operativizar todo el planteamiento anterior, es necesario diferenciar la información ambientalmente significante de la información captable realmente.

Por ejemplo, en el caso de la lluvia, ella puede aportar una proporción adecuada de agua para una semilla determinada de pasto que puede ser el indicador de un período más o menos largo de humedad. Esta información podría activar los mecanismos de germinación de la futura planta para un período de crecimiento acelerado, típico de los inicios de la vida. Se reblandece así el tejido caroténico, aparece el embrión y se activa aceleradamente la respiración y absorción de nutrientes.

Sin embargo, para nosotros no es posible medir o captar esta información, ya que sólo disponemos de los montos medidos día a día en una estación meteorológica más o menos cerca y no representativa.

Por lo tanto, es necesario diferenciar lo que es información ambientalmente relevante, de los bioindicadores; es decir, información 
socialmente producida con posibilidades de ser captada y manipulada y que en cierto grado, emula la información ambiental relevante que fluye en el ecosistema.

Si concebimos a los Parques Nacionales y otras áreas bajo régimen especial como fuentes de servicios turísticos para las comunidades del resto del territorio en donde están insertas, hace falta entonces utilizar otros criterios para delimitarlas.

Esto sería válido, también, para las áreas adyacentes y limítrofes ya que no podrían seguirse viendo como buffers o "colchones de protección que evitan la penetración a ellas de agentes indeseables", sino como áreas de contacto que favorezcan la comunicación con las otras áreas del territorio, estén protegidas o no.

Todo esto significa asumir un enfoque informático de los ecosistemas involucrados. Esto significa determinar las fuentes, medios, canales y destinos de la información que circula en ellos, así como también su significado para cada una de las especies y, por supuesto, para la actividad humana.

La información dentro de un ecosistema puede ser entendida como una "variación significativa de un quántum de energía que puede ser de los más variados tipos: físico, química, biológica. Al igual el diferencial de tiempo, puede ser muy corto o muy largo".

Lo importante de este enfoque es determinar cómo esta variación de energía y por ende de información, es capaz de desencadenar o detener procesos físico-químicos o biológicos que a fin de cuentas, determinan la dinámica de los ecosistemas.

En el cuadro siguiente, aparecen una serie de fuentes de información que, a través de diferentes medios o canales, pueden activar o desactivar procesos en los ecosistemas.
Fuentes, canales o medios de transmisión y

significado de la información ambiental

\begin{tabular}{lll} 
FUENTE & \multicolumn{1}{c}{ MEDIO } & SIGNIFICADOS \\
GENETICA & FLUJOS & TIPOS DE \\
& FITOGEOGRA- & COBERTURA \\
& FICOS O & \\
& FUERZAS DE \\
& DISPERSION.
\end{tabular}

TERMICA

METEOROLO -

ACTIVACION DE GIA

PROCESOS DE

REPRODUCCION

O FRUTIFICCION

QUIMICA LLUVIAS, GERMINACION O

U SOBRE TODO PROCESO DE

OXIDACION LAS PRIMERAS PERDIDA DE

FOLLAJE

$\begin{array}{lll}\text { COMPOSI- } & \text { CAMBIOS DE } & \text { MIGRACIONES } \\ \text { CION } & \text { SALINIDAD EN } & \text { DE PECES EN } \\ \text { IONICA } & \text { EL AGUA } & \text { ESTUARIOS }\end{array}$

Fuente: Elaboración propia.

En informes anteriores Ovalles (1992), se hizo una evaluación concreta de cada uno de estos ecosistemas y destacaremos ahora, cómo los flujos de información desencadenan o detienen procesos vitales en ellos.

Pero antes, profundizaremos sobre el significado de utilizar esta información para la cabal concepción y manejo de unidades de ecoturismo.

El grado de sustentabilidad de una actividad económica y en caso concreto de una unidad de ecoturismo, podría ser medido por el uso de esta información ambiental en el proceso de toma de decisiones.

En el momento en que una alta proporción de decisiones significativas de la unidad de 
turismo, se asumen tomando en cuenta esta información ambiental proveniente de los ecosistemas, quiere decir que se están respetando sus ciclos $y$, lo que es más importante, se están haciendo las modificaciones necesarias en la organización del proceso productivo para que este sea intrínsecamente ambiental.

En caso contrario, habrá un desaprovechamiento de este potencial y seguramente, se sucederán graves daños ambientales.

Este enfoque contrasta con la común concepción de lo ambiental, en la cual se trata sólo de proteger áreas o tomar previsiones para minimizar el impacto ambiental de las actividades económicas, pero se deja de lado, la posibilidad de reestructurar internamente el proceso turístico y su organización.

El éxito de una unidad de turismo hasta ahora ha sido mediado por la óptima proporción de factores productivos; es decir, tecnologíacapital-materias primas y mano de obra.

Los métodos para hacer eficiente el proceso estaban basados en las técnicas de sistematización, su artificialización y control supervisado.

Estas técnicas, típicas de una etapa de producción en masa, homogeneizada, de bajo costo unitario y de supeditación de la mano de obra al proceso tecnológico llega a su fin con la crisis de energía de finales de la década del 70 y con la crisis económica de los 80 , que replantean todo el proceso.

Lo que hasta esta fecha significaba para el modelo el control de la energía, pierde vigencia con la posibilidad real y efectiva de que el flujo de información ambiental mejore el uso de la energía y otros insumos productivos. Cambió así la lógica de los procesos de organización del trabajo y permite hoy modificar las estructuras y escalas de trabajo.

En este caso, no se trata sólo de información genérica, sino cualquier otro nuevo flujo de información ambiental que tienda a modificar cualquier estructura organizacional o que cree las condiciones necesarias para modificar la cultura de la organización, sus objetivos e, incluso, su misión.

La información ambiental, que en la sección anterior significaba un dato, es decir, variaciones significativas de energía en una unidad de tiempo, puede ser utilizada en una organización para evaluar la posibilidad de coordinar más estrechamente actividades productivas, controlar procesos tecnológicos, racionalizar el empleo de materias primas, monitorear entornos, manejar temporalmente, delegar, tomar decisiones, anticipar escenarios, ampliar radios de acción; en fin, potenciar fortalezas, minimizar debilidades e incluso, cambiar el rol de la organización turística.

Esta información ambiental significativa es algo más que data, implica significado, lo que quiere decir que para algún sujeto dentro de la organización, se le está diciendo algo relevante en cuanto a su función y por lo tanto, podrá hacerla de otra manera, e incluso mejor.

Para la organización ecoturística como un todo, la información significativa representa una mayor posibilidad de actuar coordinadamente en función de los objetivos que se han dado y en un ambiente incierto y turbulento, el cual, por cierto, también emite información.

Para las organizaciones ecoturísticas posibles y que estén vinculadas estrechamente al ambiente, tales como: el ecoturismo y otras, poder captar información ambiental relevante es fundamental para poder guiarse por ella, y hacerla así parte consustancial de su misión; si está pensada en términos de desarrollo sustentable.

En fin, esta propuesta significa crear las condiciones concretas que permitan poder generar, captar, transmitir, procesar, archivar y desplegar los bioindicadores que representan un flujo de información ambiental de los ecosistemas menos intervenidos y poder traducirlo en indicadores de gestión que permitan reconvertir el 
proceso productivo y por ende, su reorganización sobre nuevas bases.

Los indicadores de gestión no sólo se refieren a evaluadores de los procesos administrativos, sino como se expresa en el libro La Administración en una página Khanden, $\mathbf{R}$ (1991) son la guía indispensable para un trabajo en equipo altamente flexible e innovativo, tal y como el que requieren hoy en día las organizaciones turísticas.

El proceso de reconversión de las unidades turísticas, a partir de la información ambiental que aporten los núcleos de las AREAS, a través de las áreas buffer, implican cambios organizacionales desde la misión hasta los procedimientos e incluye las tecnologías, materias primas, localizaciones, mercados, remuneraciones, etc.

Todo esto requiere de un flujo constante de información ambiental que no se limita a los sistemas computarizados, sino que incluye formas de comunicación personal y grupal directa. Por estas razones, proponemos una serie de programas para la zona buffer que viabilicen este flujo.

Para la protección de estas especies se han delimitado zonas de conservación estricta bajo la figura de NUCLEO, que coincide con los mejores ecosistemas de los Parques Nacionales.

Por otro lado, se han delimitado una serie de zonas productivas que conservan modos interesantes de relacionamiento entre la sociedad y su entorno y en las cuales existen diversas unidades de producción que requieren de los servicios ecológicos de las otras zonas.

2.2.3. Las áreas de amortiguación como respuesta al proceso de ocupación de las áreas ambientales protegidas -

En varios países del mundo, los reglamentos de los Parques Nacionales y sus áreas adyacentes poseen una legislación específica que garantiza su integridad, pero que permite su utilización y así se convierten en áreas ideales para explorar, bajo control, las posibilidades del desarrollo sustentable, es decir los métodos de trabajo conducentes a la creación de estilos productivos que se supeditan a los principios rectores básicos del ecosistema involucrado y se limitan a administrar activamente las potencialidades y restricciones que ofrece el ambiente; antes de sustituirlo.

De esta manera, el paisaje resultante será adecuado a las condicionantes ecológicas, pero deberá respetar las necesidades locales y regionales; dándole sentido a la protección del ambiente bajo un punto de vista social.

Por ejemplo, en la República Dominicana, se denominan "zonas de transición" y se basan en el principio del "not net loss", en el cual el standard de vida de la gente debe mejorar a la par de la conservación del área ambiental protegida.

Según los italianos, la zona "buffer" es un área de transición con una gran biodiversidad y con conexión directa con el AREA. Allí es posible establecer índices para determinar sus ocupaciones.

En Sinharaja, India, se creó un buffer de $3 \mathrm{Km}$ de ancho para actividades forestales de los residentes para techar las cabañas. Se incluyen parcelas de demostración agroforestal e instalaciones básicas de salud y educación.

Arias (1993) de Panamá, diferencia la función amortiguadora de áreas internas de un parque, de área de amortiguamiento creada ex profeso en un lindero de él. Destaca que no se deben declarar sólo con criterios conservacionistas, sino en función de las necesidades de los pobladores locales tradicionales. Ellas recogen las instalaciones necesarias para las relaciones entre los pobladores adyacentes y las áreas protegidas.

En USA se han emprendido estudios de 
áreas adyacentes a los parques nacionales de manera de precisar límites, incluir recursos no protegidos y registrar visuales. Esto implica reconsiderar el parque en un contexto más amplio.

En Asia, las zonas buffer se hacen fuera de los parques para evitar los conflictos con los pobladores locales y son de absoluta injerencia de los problemas municipales. Kozlowski (1993).

Pero en la mayoría de los casos, relata Kozlowski (1993), la planificación de las áreas se hace en función de defender el parque y de proyectarlo hacia la comunidad.

Otra función de los buffers es servir de área de expansión a poblaciones de fauna silvestre, que no pueden ser viables si están sólo confinadas a los linderos de los parques. Esto tiene que ver con la etología y ecología animal de estas especies.

La efectividad de un buffer como protector del parque, depende de la compatibilidad de sus usos y lo propuesto en el plan de ordenamiento del parque para el área adyacente.

En Perú, el Parque Manu también ha definido su área de amortiguamiento para el uso de las comunidades indígenas.

En Indonesia, se involucra a la población que vive en los buffers en el manejo de los parques. También se hacen estudios de costo / beneficio de las actividades locales, antes y después de la implantación del parque.

En España, se han definido "áreas de influencia socioeconómicas" de los parques, en la cuales, se mide las necesidades y se estiman las medidas compensatorias necesarias para resarcir a la población de los daños que pudiere causar la declaratoria del parque.

Dentro de una Reserva Biósfera, los Parques Nacionales y las "zonas de amortiguación" generan una gradación desde los usos más restrictivos como los del área primitiva o núcleo de la reserva hasta las zonas de usos extensivos, intensivos y de servicios.

Otra figura jurídica interesante son las "áreas de restauración" para aquellas áreas degradadas que se quieren recuperar haciendo uso de la "ecología de la regeneración".

En fin, estas son algunas experiencias que destacan que los parques, no pueden ser considerados "espacios sin habitantes", como el título del libro de Thora Amend (1993), y más bien es posible viabilizar selectivamente su uso turístico.

\subsubsection{Evaluaciones de las capacidades de carga a nivel regional.}

La presente sección contiene las especificaciones de las técnicas de evaluación de capacidades de carga de visitantes, elemento clave para la definición y formulación de AREAS DE ECOTURISMO.

Este trabajo se realiza tomando en cuenta la caracterización de línea base (Etapa 3) y la definición de las áreas (Etapa 4); tanto para cumplir con los objetivos de la UNESCO-UICN como de las propuestas de uso para el área que se derivan del reglamento. En este sentido hace falta una serie de indicadores que le impongan límites técnicos y económicos a las actividades turísticas.

Estos indicadores permitirian evaluar la capacidad de carga de los ecosistemas más frágiles, pudiéndose utilizar luego, la metodología propuesta para evaluar otros ecosistemas presentes.

Sin embargo, la evaluación de capacidad de carga se hace por métodos indirectos que miden los impactos de visitantes, ya que queremos superar una visión fuertemente biologista del problema. 
Desde hace algunos años, las Ciencias Agronómicas han venido utilizando una serie de indicadores para medir el tamaño óptimo del rebaño que pudiese pastar en determinadas condiciones ecológicas de las sabanas y para diferentes tipos de pasto. Utilizando las llamadas unidades animales (U/A), era posible determinar el número de cabezas por hectáreas y decidir los sistemas de manejo del pastizal. En nuestro caso el principal agente analizado es el visitante.

Por otro lado, las Ciencias Ecológicas y en especial la Ecología de Poblaciones Animales, estima una serie de índices de capacidad de carga de ecosistemas, de manera de determinar su grado de estabilidad y sus riesgos de afectación.

Más recientemente, los expertos en ecología de la conservación, comenzaron a plantear hipótesis sobre poblaciones animales viables dentro de áreas protegidas, lo cual implicaba determinar la ecobase de recursos necesaria para mantener los procesos vitales de una determinada especie.

Sin embargo, esos estudios han sido referidos sólo a poblaciones animales y no a actividades humanas que implican el manejo de tecnologías y sistemas de gestión que pueden dar como resultados, índices muy diferentes.

El manejo de visitantes en áreas protegidas como los Parques Nacionales o en las playas, favoreció las transferencias de este concepto de capacidad de carga al campo de la ecología humana; dada la necesidad de estimar poblaciones tope de visitantes, tiempo de recuperación y de visitación de lugares, tasas de ingreso, daños permisibles, etc.

Sin embargo, es poco lo que se ha avanzado en esta materia; mientras grandes proyectos de desarrollo turístico amenazan con impactar los ecosistemas. Por otro lado, proponen y se experimentan modalidades nuevas de asentamiento y desarrollo turístico, sin una clara idea de la capacidad de respuesta de los ecosistemas.
La determinación de los índices de capacidad de carga para los ecosistemas no se realiza hoy día bajo los parámetros de un método experimental de parcelas muestra, a las cuales se les mide en forma controlada, las variaciones de una serie de características que nos indican el estado del ecosistema ante diferentes afluencias de visitantes $y / 0$ usuarios. Este método cuasi experimental es muy costoso y complejo.

Se procede entonces a utilizar las metodologías de límites aceptables de daños, que permiten una aproximación más rápida y eficiente al problema. De la caracterización de Línea Base se recopila información bibliográfica sobre el comportamiento, estructura y dinámica de los ecosistemas analizados o ecosistemas similares, tratando de determinar sus niveles de resilencia y el posible lapso de recuperación.

Se confrontaron ambos tipos de resultados, con los de campo y los de investigación documental, tratando de establecer límites aceptables de daños para las diversas modalidades de usos y de manejo. Para poder evaluar los impactos en los ecosistemas se seleccionan varios sectores del área que estuvieran sometidas a una presión de visitantes y/o usuarios importantes.

Según la Organización Mundial del Turismo y su Comité Ambiental (1992), la capacidad de carga es el "nivel de visitantes e infraestructura que un área puede tener con altos niveles de satisfacción para los usuarios y pocos impactos ambientales sobre los recursos".

Del mismo modo, para la Universidad Autónoma de Madrid y en especial para el Departamento de Ecología (1991), la capacidad de carga es la "densidad máxima de visitantes que puede albergar un área sin alterar en forma irreversible, sus valores ecológicos".

En el libro Nature Tourism, Managing for the Environment, editado por Tensie Whelan (1991), se plantea que la integridad de las áreas protegidas, irónicamente depende de las 
limitaciones al uso y que ellas sí tienen un límite absoluto. Esta capacidad de carga depende del número y las características del visitante.

Estas tres definiciones todavía conservan una fuerte carga biologística, por lo que se requiere de metodologías más complejas de determinación de la capacidad de carga que tome en cuenta a los factores humanos. Una de ellas, es la esbozada por Elizabeth Boo en su texto "Ecotourism Planning for Protected Areas" (1993). En este caso, después de realizarse en forma participativa un taller para determinar el "assess the current situation" de un Parque Nacional, se procede a determinar el nivel de turismo deseable.

También, en forma de taller participativo, se especifican las actividades que los visitantes querrían o podrían hacer en el área; los niveles de servicios ofrecidos por ésta y el grado de perturbación de los ecosistemas, para así ir determinando el número apropiado.

Este número de visitantes apropiado estaría en función también de los objetivos del área protegida, las posibilidades de tener recursos para su real protección o restauración y las demandas y necesidades insatisfechas de la población local, que podrían ser resueltas con los aportes de los visitantes.

Una vez logrado un consenso, se elaboraría un plan de manejo con actividades que garanticen que no se afectará el acosistema protegido más allá del nivel establecido. Un sistema de monitoreo permitiría evaluar continuamente la bondad de las decisiones tomadas y los problemas que se vienen presentando.

Una experiencia similar se usó en el Parque Nacional Galápagos en el Ecuador y es relatado por George Wallace, en su trabajo Visitor Management: Lessons from Galápagos National Park (1993). En este caso, se usa el indicador límite aceptable de daños para superar las dificultades que presentan los índices de capacidad de carga para evaluar afluencias de visitantes.
El afirma que no hay correlación entre el número de visitantes y el nivel de impactos en un ecosistema, ya que ellos dependen de otros factores como sus motivaciones y conductas. Por otro lado, la existencia de infraestructura de manejo de visitantes, expectativas de visita, duración, etc., inciden en los resultados.

Por eso plantea, más bien, determinar sólo el límite de impacto inaceptable y cerrar el área a la visita con cualquier nivel poblacional.

Para calcular el límite aceptable de daños, se procede a identificar indicadores que miden la posible afectación del componente ambiental por parte del visitante. Luego, se establecen los estándares aceptables de cada indicador, según la capacidad de manejo que tenga la autoridad responsable en el área.

Para ver si los indicadores exceden los estándares, se establece el monitoreo, a partir de estudios de línea base de los diferentes ecosistemas del área, con un sistema de información que ofrezca en tiempo real datos de su condición. Wallace (1992) opina que este indicador "le ofrece más elementos al administrador del área que un simple índice de capacidad de carga".

Alan Graefe, Fred Kuss y Jerry Vaske, en su metodología Directrices en el Impacto de Visitantes (1991), ofrece un método similar, al igual que Stanley G., Cole N., Lucas M., Peterson M. Y Frisells, en el trabajo The Limits of Acceptable Change, System for Wilderness Planning (1992).

En el primer caso, se establecen ocho principios básicos y veintidós corolarios para guiar cualquier acción de impacto de visitantes (ver Gráfico).

De allí, desarrollamos una metodología bastante sencilla para determinar una serie de directrices de manejo de visitantes, casi sin establecer límites de acceso absolutos, sino más bien, aquellos niveles de visitantes que las prácticas de manejo pudieran permitir, sin perder la integridad del ecosistema visitado. 


\section{Principios y corolarios de la evaluación}

\section{del impacto de visitantes}

Para ampliar esta información, sería recomendable analizar la profusa obra: Visitor Impact Management a Systematic Approach to Recreational Carrying Capacity" editado por la National Park and Conservation Association (1992).

\begin{tabular}{|c|c|}
\hline PRINCIPIO & COROLARIOS \\
\hline $\begin{array}{l}\text { 1. Hay que identificar } \\
\text { cambios inacepta- } \\
\text { bles. }\end{array}$ & $\begin{array}{l}\text { 1A. No hay límite } \\
\text { absoluto. } \\
\text { 1B. Hay que hacer } \\
\text { balance }\end{array}$ \\
\hline $\begin{array}{l}\text { 2. El control de } \\
\text { impacto es parte de } \\
\text { la planificación. }\end{array}$ & $\begin{array}{l}\text { 2A . El control de } \\
\text { impacto es parte } \\
\text { del manejo. } \\
\text { 2B. El control de } \\
\text { impacto influye en } \\
\text { el "zoning" y } \\
\text { asignación } \\
\text { de recursos. }\end{array}$ \\
\hline $\begin{array}{l}\text { 3. El control de } \\
\text { impacto es complejo } \\
\text { y requiere informa- } \\
\text { ción científica. }\end{array}$ & $\begin{array}{l}\text { 3A. No hay } \\
\text { requerimientos } \\
\text { absolutos de datos. } \\
\text { 3B. Hay diferentes } \\
\text { niveles de } \\
\text { información a captar. }\end{array}$ \\
\hline $\begin{array}{l}\text { 4. El paso crítico es } \\
\text { la definición de obje- } \\
\text { tivos. }\end{array}$ & $\begin{array}{l}\text { 4A. Los objetivos } \\
\text { requieren } \\
\text { indicadores. } \\
\text { 4B.Los indicadores } \\
\text { se traducen en } \\
\text { normas. }\end{array}$ \\
\hline $\begin{array}{l}\text { 5. Los problemas del } \\
\text { impacto de visi- } \\
\text { tantes, se identifican } \\
\text { comparando niveles } \\
\text { aceptables con } \\
\text { índices claves. }\end{array}$ & $\begin{array}{l}\text { 5A.Hay que tomar en } \\
\text { cuenta rangos } \\
\text { amplios de posibles } \\
\text { impactos. } \\
\text { 5B.Hay que } \\
\text { esmerarse en los } \\
\text { niveles críticos de } \\
\text { impactos. }\end{array}$ \\
\hline
\end{tabular}

6. Las decisiones a tomar, requieren de recursos y el conocimiento de las interrelaciones entre impactos.

7. Los impactos indeseados pueden ser subsanados con diversas técnicas.

8. Cuando se determinan objetivos de control hace falta tomar en cuenta la diversidad de situaciones posibles.

\section{A. Pueden haber impactos no causa- dos por el visitante. 6B. Hay que identi- ficar la relación entre índice clave $y$ patrones de uso del visitante. \\ 6C. La capacidad de uso es variable. \\ 6D.Es necesario medir potencial rege- nerativo.}

7A. La capacidad y el límite de uso no son las únicas vías.

7B. Las técnicas de manejo de impacto pueden causar otros impactos.

7C. La selección de las técnicas es muy compleja.

7D. Las técnicas indirectas de control pueden sustituirse.

8A.Cada área está relacionada con otras. 8B.Es necesario pensar en un enfoque de sistemas de áreas.

8 C. Hay que darle viabilidad a las restricciones de visitantes impuestas.

8D.No se debe pensar que el límite aceptable es el óptimo.

Fuente: Alan Graefe, et al., op. cit. 1991. 
Omar Ovalles

Facultad de Arquitectura Universidad Central de Venezuela Oovalles@villanueva.arg.ucv.ve 